\title{
Short-Term Study Abroad: The Storied Experiences of Teacher Candidates From Japan
}

\author{
Scott Roy Douglas, Fujiko Sano, and Mark Rosvold
}

\begin{abstract}
The story extracts presented here reflect the experiences of five teacher candidates from Japan on a shortterm study abroad program focusing on developing English-language skills while exploring Canadian culture and English-language teaching methods. Narrative inquiry techniques were employed to gather data related to the participants' program experiences. These data were crafted into stories with participant input and review. The story extracts relate to intercultural interactions, First Nations culture, teaching methods, meals, and extracurricular activities. On reflection, the narrative inquiry process employed in this study worked as both a research and pedagogical tool to uncover meaningful program experiences.
\end{abstract}

I was on the tarmac. My eyes blinked at the bright sun reflected from the plane as I looked back at my two friends climbing down the metal stairs. We stood together a few minutes, disoriented by the new surroundings, before we followed a small string of people into the terminal, down a long corridor, and through a set of glass doors. At the front of a waiting crowd was a tall blond guy about our age. He came right up to us, told us his name was David, and ushered us towards the baggage carousels. When we pointed, he lifted our bags off the conveyer belt, and then led us out the front door. He asked us questions the whole time while we pulled our bags behind us. I could feel myself stumbling over a sudden and expansive use of English. Outside, a female taxi driver took my bag from my hand. We were crammed into the back seat of a yellow cab, and David climbed in front as he continued to talk and ask questions. Minutes later, we arrived at Pacific Interior University ...

And thus, Gida began her short-term study abroad program in British Columbia, Canada. This paper presents excerpts from five stories created as a result of a narrative inquiry into a two-week short-term study abroad program designed for teacher candidates from a university in Japan. Canada is a popular destination for international students, and British Columbia welcomes around one third of all international students coming to this country. In British Columbia, over 130,000 international students with study permits attended educational institutions in 2015, with 6,555 of those students coming from Japan (British Columbia Ministry of Advanced Education, Skills \& Training, 2017). However, because they do not need a study permit, those numbers do not include students coming to British Columbia for six months or less, such as the participants in the current study. Exact numbers for students studying short term in British Columbia are difficult to estimate.

The short-term study abroad program in this paper is part of a growing trend of short-term study abroad programs that are attractive to international students because they offer a chance to study in another language without interrupting their main university studies (Jackson, 2008). Nevertheless, these programs still represent a significant time and financial investment, along with the effort of studying in an additional 
language, to university students. This investment in time, money, and effort calls for research that can inform the crafting of the best possible short-term study abroad experiences for learners (Douglas, 2015).

The purpose of the current study was to explore the potential of narrative inquiry (Benson, 2014; Clandinin \& Connelly, 2000; Polkinghorne, 1995) as a pedagogical and a research tool for creating accounts of short-term study abroad experiences with teacher candidates from Japan. A further goal was to obtain a better understanding of the short-term study abroad experiences from the point of view of participants themselves. As such, the guiding inquiry question was as follows: "What were the storied experiences of teacher candidates on a short-term study abroad program designed to develop both English-language skills and content knowledge?"

The narrative excerpts presented in the results section are an attempt at answering the above question by providing a window into the storied lives of the participants during the program.

\section{Background}

\section{Short-Term Study Abroad}

The short-term study abroad program that is the focus of this paper lies within a broad definition of shortterm study abroad programs that typically last less than four to six weeks, focus on additional language learning, and take place within a postsecondary context (Douglas, 2015). However, it is not easy to generalize the short-term study abroad experience. Jackson (2008) has pointed out that there are many manifestations of short-term study abroad programs, and it is difficult to stay abreast of the diverse number of complex variables affecting students. These variables can include instructional practices, student accommodations, interpersonal relationships, and program length (Churchill \& Dufon, 2006).

By and large, a number of positive outcomes resulting from the short-term study abroad experience have been found. Jackson (2008) has reported that when students were able to engage in the language and culture around them, a short-term study abroad experience could have a profound impact on the participants. It has also been reported that university students on a summer program learning French were able to improve their language skills and lower their anxiety levels (Allen \& Herron, 2003). Another summer English-language program for university students from Korea significantly improved learners' willingness to communicate, speaking skills, and interaction in class (Kang, 2014). Oral fluency, accuracy, and listening comprehension gains were similarly evident for university English-language learners from Catalan- and Spanish-speaking backgrounds on a three- to four-week short-term study abroad program, with lower proficiency level students particularly benefiting (Llanes \& Muñoz, 2009). For preservice teachers from Hong Kong on a short-term study abroad program in New Zealand, Lee (2009) noted that participants used a large amount of English, which helped their language development and awareness of different varieties of English. The participants also interacted with people from many different backgrounds, which fostered the development of their intercultural awareness and a deeper appreciation of Indigenous culture in New Zealand. 
Along with growing additional language proficiency and intercultural competence, there can also be other benefits to short-term study abroad. Pigott (2011) has maintained that short-term study abroad programs should not only be judged based on students' improvements in their additional language proficiency. The opportunity for students to have life-enriching experiences should also be taken into account. For example, Pigott found that second-year university students from Japan experienced positive changes in their knowledge, motivation, and world-view as well as their English-language abilities during a short-term study abroad program. Short-term study abroad programs can have academic and sociopsychological impacts that go beyond additional language learning, such as changes in relationships and the development of friendships, the creation of support and social networks, the realization of having outsider viewpoints, and feelings of freedom and liberation (Gay, 2016). For preservice teachers from Hong Kong, new pedagogical understandings can also result from the short-term study abroad experience, with the gaining of new teaching and assessment strategies that can be put into participants' future teaching practice (Lee, 2009). The same participants also found that they underwent personal development, acquiring new life skills, a sense of independence, and more maturity (Lee, 2009).

The key to many of the above findings appears to be the ability to interact with the surrounding host culture. However, students may not always be able to engage in the language and culture around them. For example, Douglas (2015) found that intercultural encounters may not occur naturally and students may not have the intercultural experiences that they had anticipated. The potential for a profound wellrounded learning experience may depend on the extent to which students are welcomed into the shortterm study abroad context (Kinginger, 2009). For example, students on a short-term study abroad program may have strong desires to directly experience the host culture, but there may not be many opportunities for them to interact with that culture, as was the case for a group of university students from Japan (Horness, 2014). Kato and Reeder (2015) noticed that for some university students from Japan studying in Canada, their expectations for multiple opportunities to interact with people from native Englishspeaking backgrounds were not met, and even challenged by a multicultural context in which labels of native and nonnative English speakers did not align with preconceived understandings. This mismatch between preconceptions and reality put the onus on students to create their own opportunities to use and improve their English. In another study, some students from Japan studying in New Zealand also did not have as many opportunities to use English outside of class as they expected, even when they were in a homestay environment. This may have been because of their limited English-language abilities, but it may also have depended on how much local users of English were willing to adjust to learners' Englishlanguage proficiency levels. Local attitudes seemed to play a role in the number and quality of Englishlanguage interactions for the participants outside of class (Tanaka, 2007). Finally, there have been studies showing that a short-term study abroad program may even have the opposite of the desired effect. Trent (2011) found that, for some preservice teachers from Hong Kong, short-term study abroad experiences could lead to identity conflicts and antagonistic feelings between how teaching was conceived at home versus the short-term study abroad context. In fact, it may have even led to preservice teachers reconsidering whether they still wanted to become teachers in their home countries. Nevertheless, Trent reported that short-term study abroad plays a role in contributing to the development of teacher identities. While it can be challenging, Trent found that increases in language proficiency and 
cultural knowledge contributed to participants consolidating their identity as English-language teachers. For Trent, the short-term study abroad experience was part of an overall trajectory of teacher identity development taking place both at home and abroad.

To create a successful short-term study abroad program, Benson, Barhuizen, Bodycott, and Brown (2013) have put forward that interactions with the local community, support for students' additional language learning identities, increased intercultural encounters, control over the learning experience, engagement in goal-setting, and realization of hopes and wishes, are part of a complex formula for creating positive short-term study abroad experiences. Above all, students expect interactions with the host community, and the potential for having these interactions and advancing their additional language skills is what often motivates them to go abroad. In exploring the perceptions of undergraduate students from Japan on a short-term study abroad program in Canada, Douglas (2015) found that meaningful intercultural encounters, content-rich classroom experiences, and a wide range of extracurricular activities were the three most important elements of a successful program. However, Douglas pointed out that these meaningful intercultural encounters might not always take place and engaging extracurricular activities cannot be left to chance. Similarly exploring the experiences of university students from Japan in Canada, Kato and Reeder (2015) emphasized that institutions offering programs for Japanese learners of English should take student expectations as well as the adaptation process into account to maximize the benefit students receive from their study abroad experience. Along these lines, Allen and Herron (2003) have endorsed summer short-term study abroad programs for developing language skills, but have emphasized that nonacademic factors related to the experience should be considered along with an understanding of the importance of interacting with users of the target language both inside and outside of class to encourage language acquisition and changes in outlook.

\section{Theoretical Framework}

An additional language socialization framework can aid in the examination of how developing additional language skills and other kinds of knowledge are gained through and in the target language (Duff \& Talmy, 2011). This framework takes into account a socio-cognitive perspective of language acquisition (Atkinson, 2011) that focuses on the contexts for additional language learning along with its social, cognitive, and cultural aspects. It is the process by which learners develop their English-language skills through community membership and legitimate participation in the surrounding society (Duff, 2007). Participation in the local community is highlighted as an important aspect of how learning takes place (Lave \& Wenger, 1991; Wenger, 1998). This community participation facilitates additional language learning when, along with having access to comprehensible input in low-stress situations (Krashen, 1982), students are able to communicate and negotiate meaning with other more competent users of the target language (Long, 1996). Thus, a metaphorical space can be created to bridge what additional language learners can do independently and what they can do in collaboration with others (Vygotsky, 1978). As such, the extent to which additional language learners are able to access opportunities for meaningful interaction through their membership and perceived legitimacy in the target community is an important aspect of additional language learning (Duff \& Kobayashi, 2010). 


\section{The Study}

\section{Participants}

The five participants were all third-year teacher candidates from national universities in the Kanto region of Japan, with the goal of becoming junior high school or high school English as an additional language teachers on graduation. Four of the participants were female, and one was male. On average, they were 21 years old. The professor who accompanied them from Japan estimated they were all able to use English independently at approximately a B2 level on the Common European Framework of Reference for Languages. All of the participants chose pseudonyms for this study, with the names of the people with whom they interacted also changed to protect their identities. Table 1 briefly describes the participants, along with some of the key people in the story extracts.

\section{Table 1}

\section{Descriptions of Participants and Key People from the Story Extracts}

\begin{tabular}{lll}
\hline Name & Role & Description \\
\hline Gida & Participant & Female teacher candidate \\
Miyako & Participant & Female teacher candidate \\
Sakura & Participant & Female teacher candidate. \\
Tamoka & Participant & Female teacher candidate \\
Yuki & Participant & Male teacher candidate \\
David & Activity Coordinator & Local undergraduate student \\
Brett & Assistant Professor & Local Education faculty member \\
Sally & Instructor & Morning Canadian and Cultural Studies teacher \\
Anne & Instructor & Afternoon Language Teaching Methods teacher \\
Prof. Motoyama & Professor & Accompanying education professor from Japan \\
\hline
\end{tabular}

\section{Research Setting}

The two-week short-term study abroad program took place during the summer session on one of the campuses of a research-intensive public university in British Columbia, Canada. The campus is given the pseudonym Pacific Interior University (PIU). The program was designed for teacher candidates from non-English speaking backgrounds specializing in teaching English as an additional language in Japanese K-12 settings. The program integrated language and content learning objectives, with the goal of developing participants' English-language skills while also learning academic content. Mornings consisted of 2.5-hour seminars related to Canadian and cultural studies, and afternoons consisted of 2.5-hour seminars that focused on additional language teaching methods. Mornings and afternoons had different instructors. Other educational programming included museum visits, guest speakers, and participation in local teacher education classes. Participants lived in student residences on campus, and a full program of evening and weekend activities were also organized, such as winery tours, visits to farmer's markets, hiking trips, time at the beach, café breaks, sports activities, concert attendance, restaurant outings, festival attendance, and shopping. 


\section{Narrative Inquiry}

Narrative inquiry is a form of research endeavour in which stories are the central focus for data gathering and analysis (Benson, 2014). It can involve "portraying people living in and through a situation" (Kim \& Macintyre Latta, 2010, p. 69). The current research design focused on describing the lives of the participants, collecting and recounting their stories, and creating narratives of their experiences (Connelly \& Clandinin, 1990). To create the narratives, "descriptions of events through interviews and observations [were synthesized] into narrative or stories.... the [stories were] the outcome of the research..." (Gay, Mills, \& Airasian, 2012, p. 402). The stories were created to make sense out of the gathered data (Polkinghorne, 1995), and used as a "form for the presentation of research findings" (Benson, 2014, p. 155). The merits of this kind of narrative research lie in the ability of the stories to engage readers and allow them to develop their own interpretations based on those stories (Benson, 2013). Benson further maintained that storied narratives have the potential to count "as the findings of a study without further analysis" (p. 162).

\section{Data Collection and Analysis}

On receiving approval from the institution's research ethics board, data were gathered through multiple ways, including semi-structured interviews, short final interviews, and the sharing of oral and written anecdotes. These sources of information were transcribed for analysis. To promote trustworthiness, these data were triangulated with further data collection consisting of researcher observations of classroom, field trip, and extracurricular activities as well as attendance at the program orientation, final presentation, and closing reception. Detailed research notes were kept. Finally, the lead researcher gathered artifacts from the program, such as course outlines and timetables to complete the data collection.

To create the first draft of the stories, the transcriptions were reviewed, and key elements of the participants' experiences were annotated for inclusion in the narratives. Data were organized so that they followed a chronological sequence, with particular note to where the stories took place, who were in the stories, what happened in the stories, and what meaningful moments occurred in the stories (Gay, Mills, \& Airasian, 2012). A research assistant created the first drafts of the stories, which were then reviewed by the researchers and revised based on the transcript data and the lead researchers' field notes. Once the second drafts were completed, they were shared with the participants via email so that they could read, review, edit, and contribute further to the narratives. This review supported the validity of the stories and lessened the discrepancies between the stories the participants initially shared and the stories the researchers reported (Clandinin \& Connelly, 2000). At the end of the project, all participants received a finished version of their story via email. The final stories were around 1000 words each. Extracts of approximately 300 words each (edited for length) are presented below. 
Short-Term Study Abroad: The Storied Experiences of Teacher Candidates From Japan

\section{Results: Story Extracts}

\section{Gida: Interactions Over Ice Cream}

One day after class, Miyako, Tamoka, and I caught the bus from PIU's campus to go downtown. It was a hot day, so we all wanted to get some ice cream. We watched carefully for the correct bus stop, and we soon all got off the bus. The ice cream shop was on main street, about a block away, and we walked along the wide sidewalks past clothing shops and busy restaurants to get there. At the ice cream shop, there was a bit of a line, but it gave us time to look in the long refrigerated glass cases filled with bright flavours in plastic tubs. We each chose something new when it was our turn, paid the young teenager working the till, and then went outside into the hot sun. I had a cone with two scoops: cookies and cream on top of banana fudge. As soon as we left the shop, my ice cream was already starting to melt, and I offered, in English, to share a lick with my friends. We all exchanged cones and had a taste. I guess we were kind of loud because behind me, as I was licking Tomoka's ice cream, an older man with a funny smile came over and asked me if he could have some too. I turned around and laughed awkwardly. I didn't know what to say. He grinned, said something I didn't quite catch, and walked away leaving us to eat our ice cream cones in the sun. I was surprised he spoke to us, but people around here in shops and on the bus always seem to be making comments or saying something to me and my friends.

\section{Miyako: Discovering First Nations Culture}

We all got into a little rented bus, and we crossed the long bridge over the lake to the local First Nations museum. The museum was in a two-storey building made of rough pale stone, with a large blue sign in the local Indigenous language. Even though it was early in the morning, it was already hot, and on entering the museum it took my eyes a few moments to adjust to the cool atmosphere. We were greeted by the museum curator. At first we hung back, but he taught us some new words in his language and drew us in before he led us through the exhibits. I saw many colourful wool blankets hanging on the walls. I thought they might be from a long time ago, but the curator emphasized that the museum wasn't about old artifacts. Everything in the museum was filled with current meaning, and it was a place for living culture. He gathered us around a large hand-carved canoe made from a single tree. At first I was scared to touch it. I'd always been told not to touch! But the curator encouraged us to get close. I ran my hand along the side of the canoe, feeling the wood glide under my fingertips. The curator said "this canoe isn't hundreds of years old. In fact, it was carved recently, and it is still being used on the lake today." I had never imagined that these kinds of things still happened in Canada.

\section{Sakura: An Interactive Classroom}

We all sat in a jumbled u-shape of desks. Anne clicked the remote control in her hand, and an iceberg rushed into view. She described how simple words and phrases, such as greetings, could be found above the water, but some aspects of English take a long time to learn and they are under the surface of the water-just like an iceberg. Suddenly, as I was thinking about these things, Anne had us all stand up. She had written words on the whiteboard such as "mother tongue" and "English as an additional language."

LEARNing Landscapes | Spring 2018, Vol. 11 No. 21 | 133 
She asked us to think about what they meant while she gave each of us a different colour whiteboard marker and waved us to the front of the classroom. We were supposed to write our ideas up on the board. I stood close to the whiteboard, with the marker hovering in the air. I was just looking at the empty space in front of me when Anne approached from behind to encourage me to put up anything at all related to the topic. I panicked, worried I would be contradicted or corrected, but it never happened. Anne patiently waited until I wrote something on the board, praised me, and then went to see what my friends were doing. Finally, the board was filled with different coloured words, circles, and squiggly lines. We sat down to try and connect our thoughts together to create a single opinion. Anne helped us by summarizing everything and relating our points to various research studies, once in a while mentioning her own life experiences. The time went by quickly.

\section{Tamoka: Dinner in Student Residence}

I was starting to worry a lot about my final project, which was a presentation on an English lesson plan for junior high school students on global legends. The day before our final projects were due, we were working hard on our lesson plans and presentations in the big shared kitchen in our student residence. David walked into the kitchen and noticed how tired and nervous we were. He announced we needed a break, and he was going to cook dinner for us that night. He disappeared for a bit, and then came back with a bag filled with vegetables, jars, and plastic tubs. He made everyone sit down at the big square table in the kitchen and then got us washing lettuce and slicing cumbers. Once it was ready, the first thing I tried was a bit of Greek salad. The olives in the salad were great, but I noticed that Miyako, Gida, and Sakura didn't take any olives at all. They just picked out some lettuce leaves, cucumbers, tomatoes, and red onions. As the salad bowl emptied, a lot of olives were left at the bottom of the bowl. I felt bad for those olives, so I began to eat them up. Yuki and Gida jokingly said "you are an olive girl," and the whole group laughed. After we ate everything, David brought out a pecan pie for dessert. It was sweet and sticky. David saw me wince. I told him it was much sweeter than what I was used to at home, but I liked it. With that, we all started to tell David about Japanese desserts. He asked lots of questions, and it felt good answering them. Then we helped clean up the kitchen and went back to work. I wasn't so nervous about my project anymore.

\section{Yuki: Extracurricular Sports}

One day, I went across campus to the gymnasium to see if I could play basketball. There was a PIU student there playing by himself, so I asked him if he wanted to play together. We played one on one for a while, taking turns burning past each other to do a layup, or fading back and sinking a three pointer. I think I might have scored more points than him, but we weren't really keeping track. It was just fun to have a chance to play. I also had another chance to play basketball on the afternoon after the final presentations. David took all of us downtown on the bus after the final presentations. It was really hot outside, and there were lots of boats and people everywhere along the waterfront. It reminded me of an amusement park. There were even pianos on the boardwalk, and some people were playing them as we walked by. We soon found a shady spot close to the outdoor basketball courts and all sat down. 
David asked me if I was a good player, and I told him that I was just okay. David pulled a ball out of his bag, and we went onto the court. The basketball bounced loudly as it went between us. I scored a few points, but it was hot so we decided to go for a swim in the lake instead. I walked out into the lake until the water reached my chest. At that point, I turned around and saw the rest of the group relaxing and watching us from the shore.

\section{Discussion}

The five story extracts presented in this paper provide a window into the narrative experiences of the participants during a short-term study abroad program designed to promote language and content learning for teacher candidates from Japan. Glimpses into the daily lives of the participants were available to readers to see what participants thought, saw, and did themselves during the program.

In reading the stories, it seems like a number of conditions were met to create impactful experiences. For example, meaningful intercultural encounters and interactions with the local community play an important role in creating positive short-term study abroad experiences (Douglas, 2015; Benson et al., 2013). In the stories, these interactions might have just been a word or two like when Yuki asked to play basketball with a PIU student, Tomoka laughed with her friends over Greek salad, or a passerby on the street jokingly asked Gida for a taste of her ice cream, but these encounters impressed the participants enough to share them with the researchers. Some of the interactions led to deeper intercultural understandings. For example, Miyako, similar to the preservice teachers from Hong Kong who gained an increased appreciation of Indigenous culture in New Zealand (Lee, 2009), reflected on her interactions with the curator of the First Nations museum and she realized that the artefacts she saw represented a living culture she had not known still existed in Canada.

Rich content learning opportunities, such as new teaching strategies for preservice teachers, are also an element of a successful short-term study abroad program (Douglas, 2015; Lee, 2009). For example, Sakura grappled with new concepts and engaged in instructional strategies that promoted interaction related to additional language teaching methods during an afternoon class. Content learning was also seen in how the participants were invested in the assignments, such as when David had to encourage the participants to take a break from working on their final projects creating lesson plans, or the participants were learning about First Nations culture in the British Columbia interior.

A third factor recognized by Douglas (2015) as being an important element of the short-term study abroad experience was varied extracurricular activities. The little daily experiences included in the participants' narratives, such as eating ice cream, playing basketball, or eating dinner, were similar to the types of lifeenriching experiences Pigott (2011) proposed should be taken into account when judging a short-term study abroad program. The participants further seemed to be deepening their friendships and creating the networks that Gay (2016) indicated were part of the socio-psychological impacts of short-term study abroad. There was a feeling of independence in Gida's description of taking the bus, new realizations 
for Miyako as she visited the First Nations museum, engaged learning for Sakura in her afternoon class, enjoyment of good food for Tomoka, and bonding through sports for Yuki.

In the stories, the additional language socialization (Duff, 2007) of the participants could be seen in the use of their language skills to acquire knowledge and interact with community members around them and with each other. Incidents such as when the man on the street interacted with Gida or David played basketball with Yuki indicate that the participants were participating in the daily act of living and learning in the host society, and through that act, finding opportunities to use the target language. The narrative research process also became a mode for meaningful engagement in English as the participants had multiple interactions with the researchers through the interviews, their accompaniment on field trips and extracurricular activities, important program events, anecdote gathering, and attendance in select classes. These opportunities to gather data for the narratives set up a Zone of Proximal Development (Vygotsky, 1978), in which the participants collaborated with the researchers to share their lived experiences. Thus, the research act also became a pedagogical task that provided opportunities to negotiate meaning with more capable users of the target language (Long, 1996) and foster English-language development. The stories themselves became a source of comprehensible input (Krashen, 1982) for the participants as they read and reread the various drafts of the stories leading to receiving the final draft.

Narrative inquiry and the co-creation of stories appears to be a promising research and pedagogical tool for use in short-term study abroad contexts. Other researchers have also explored the possibility of research as pedagogy. For example, Jackson (2006) used the tools of ethnographic research with university students from Hong Kong during a short-term study abroad experience to facilitate improvement in additional language skills, intercultural awareness, and personal growth. In a later study, Dressler and Tweedie (2016) used dialogue journals with undergraduate students visiting a Canadian university from Japan. These journals were found to provide rich data on the short-term study abroad experience in which participants expressed their feelings, drew on out-of-class learning, and considered intercultural competence. In the current study, the stories give readers deeper insights into the livedexperiences of the teacher candidates on this program. Based on the participants' stories, it appears that interactions with the host community, intercultural encounters, content teaching and learning, and varied extracurricular activities were all aspects of a short-term study abroad program that should be fostered. Besides these insights, the act of story co-creation, in itself, appeared to become a rich task for language learning and development. Narrative ways of thinking affected teaching and learning, with the stories deepening the understanding of the short-term study abroad experience.

\section{Limitations and Future Studies}

The current narrative inquiry involved a small group of people in a specific context at a specific time. It is difficult to generalize the findings to other settings, and the goal of the current research project was focused on description and understanding for the particular participants in a particular short-term study abroad program (Gay, Mills, \& Airasian, 2012). There is also the possibility that while the researchers involved the participants in the co-creation of their stories, the participants deferred to the researchers 
when it came to decisions on the final narratives. The stories in the current study tended to stress the positive experiences of the participants. It may be that the participants were hesitant to share their negative experiences because they wanted to be polite or to avoid hurting the feelings of the researchers. It may also be that the stories in the current study were generally positive because the participants shared experiences that they thought the researchers would like to hear. In future studies, to mitigate a potential tendency for participants to focus on their positive experiences, it might be desirable to further train the participants in narrative inquiry. For example, the participants could work together to write each other's narratives in collaboration with the researchers instead of the researchers taking the lead. Furthermore, during the data-gathering stages, participants could be specifically asked to share both their positive and negative experiences during the co-construction of the stories. This inclusion of negative experiences would lead to a richer representation of the full range of experiences in the teacher candidates' stories.

The current project involved narrative analysis, in which the researchers gathered data and crafted narrative stories out of that data (Polkinghorne, 1995). Future studies may engage in the analysis of narrative in which stories are examined for common themes to create descriptions that relate to all of the stories in a collection (Polkinghorne, 1995). For example, researchers could endeavour to identify themes related to the impact of the short-term study abroad experience on the pedagogical skills and cultural content knowledge of teacher candidates taking part in such an experience. Future projects might also consider expanding the research from narrative inquiry to a full case study in which the narratives form part of the research products. As more groups of students come for short-term study abroad experiences, these programs offer a rich source for future research endeavours.

\section{References}

Allen, H.W., \& Herron, C. (2003). A mixed-methodology investigation of the linguistic and affective outcomes of summer study abroad. Foreign Language Annals, 36(3), 370-385. Retrieved from http://dx.doi.org/10.1111/j.1944-9720.2003.tb02120.x

Atkinson, D. (2011). A sociocognitive approach to second language acquisition. In D. Atkinson, (Ed.), Alternative approaches to second language acquisition. New York, NY: Routledge.

Benson, P. (2013). Narrative writing as method: Second language identity development in study abroad. In G. Barkhuizen (Ed.), Narrative research in applied linguistics (pp. 244-263). Cambridge, UK: Cambridge University Press.

Benson, P. (2014). Narrative inquiry in applied linguistics research. Annual Review of Applied Linguistics, 34, 154-170. Retrieved from http://dx.doi.org/10.1017/S0267190514000099

Benson, P., Barhuizen, G., Bodycott, P., \& Brown, J. (2013). Second language identity in narratives of study abroad. Basingstoke, UK: Palgrave Macmillan.

British Columbia Ministry of Advanced Education, Skills and Training. (2017). Factsheet: International students in BC. Retrieved from https://news.gov.bc.ca/factsheets/international-students-in-bc

Churchill, E., \& DuFon, M. (2006). Evolving threads in SA research. In M. DuFon \& E. Churchill (Eds.), Language learners in SA contexts (pp. 1-27). Clevedon, UK: Multilingual Matters. 
Clandinin, D.J., \& Connelly, F.M. (2000). Narrative inquiry: Experience and story in qualitative research. San Francisco, CA: Jossey-Bass.

Connelly, F.M., \& Clandinin, D.J. (1990). Stories of experience and narrative inquiry. Educational Researcher, 19(5), 211-253. Retrieved from http://dx.doi.org/10.3102/0013189X019005002

Douglas, S.R. (2015). Student perspectives on a short-term study abroad experience. In P. Clements, A. Krause, \& H. Brown (Eds.), JALT 2014 Conference Proceedings. Tokyo: JALT. Retrieved from http://jaltpublications.org/proceedings/articles/4708-student-perspectives-short-term-study-abroad-experience

Dressler, R., \& Tweedie, M.G. (2016). Dialogue journals in short-term study abroad: "Today I wrote my mind." TESOL Journal, 7(4), 939-967. Retrieved from http://dx.doi.org/10.1002/tesj.254

Duff, P. (2007). Second language socialization as sociocultural theory: Insights and issues. Language Teaching, 40(4), 309-319. Retrieved from http://dx.doi.org/10.1017/S0261444807004508

Duff, P., \& Kobayashi, M. (2010). The intersection of social, cognitive, and cultural processes in language learning: A second language socialization approach. In R. Batstone (Ed.), Sociocognitive perspectives on language use and language learning (pp. 75-93). Oxford, UK: Oxford University Press.

Duff, P., \& Talmy, S. (2011). Language socialization approaches to second language acquisition: Social, cultural, and linguistics development in additional languages. In D. Atikinson (Ed.), Alternative approaches to second language acquisition (pp. 95-116). New York, NY: Routledge.

Gay, L.R., Mills, G., \& Airasian, P. (2012). Educational research: Competencies for analysis and applications. Toronto, ON: Pearson.

Gay, S. (2016). Social and academic impacts of studying abroad. Osaka JALT Journal, 3, 5-18. Retrieved from http://www.osakajalt.org/storage/Osaka_JALT_Journal_2016.pdf

Horness, P. (2014). A social narrative inquiry of three Japanese university participants in a short-term study abroad program. Ryugaku: Explorations in Study Abroad, 7(1), 24-37. Retrieved from http://jalt-sa.org/PDF/7-1-Horness.pdf

Jackson, J. (2006). Ethnographic preparation for short-term study and residence in the target culture. International Journal of Intercultural Relations, 30, 77-98. Retrieved from http://dx.doi.org/10.1016/j.ijintrel.2005.07.004

Jackson, J. (2008). Language, identity and study abroad: Sociocultural perspectives. London, UK: Equinox Publishing.

Kang, D.M. (2014). The effects of study-abroad experiences on EFL learners' willingness to communicate, speaking abilities, and participation in classroom interaction. System, 42, 319-332. Retrieved from http://dx.doi.org/10.1016/j.system.2013.12.025

Kato, R., \& Reeder, K. (2015). "I didn't know who is Canadian": The shift in student expectations during the initial stages of a study abroad program. JALT Journal, 37(1), 43-58. Retrieved from http://jalt-publications.org/files/pdf-article/jj2015a-research.pdf

Kim, J.H., \& Macintyre Latta, M. (2010). Narrative inquiry: Seeking relations as modes of interactions. Journal of Educational Research, 103(2), 69-71. Retrieved from http://dx.doi.org/10.1080/00220670903323164 
Kinginger, C. (2009). Language learning and study abroad: A critical reading of the research. Basingstoke, UK: Palgrave Macmillan.

Krashen, S.D. (1982). Principles and practice in second language acquisition. New York, NY: Pergamon Press. Retrieved from http://www.sdkrashen.com/content/books/principles_and_practice.pdf

Lave, J., \& Wenger, E. (1991). Situated learning: Legitimate peripheral participation. Cambridge, UK: Cambridge University Press.

Lee, J.F.K. (2009). ESL student teachers' perceptions of a short-term overseas immersion programme. Teaching and Teacher Education, 25, 1095-1104. doi:10.1016/j.tate.2009.03.004

Llanes, A., \& Muñoz, C. (2009). A short stay abroad: Does it make a difference? System, 37, 353-365. doi:10.1016/j.system.2009.03.001

Long, M. (1996). The role of the linguistic environment in second language acquisition. In W. Ritchie \& T. Bhatia (Eds.), Handbook of second language acquisition (pp. 413-468). New York, NY: Academic Press.

Pigott, J. (2011). Towards a richer understanding of the study abroad experience. Ryugaku: Study Abroad SIG Newsletter, 4(1), 2-10.

Polkinghorne, D.E. (1995). Narrative configuration in qualitative analysis. International Journal of Qualitative Studies in Education, 8(1), 5-23. dx.doi.org/10.1080/0951839950080103

Tanaka, K. (2007). Japanese students' contact with English outside the classroom during study abroad. New Zealand Studies in Applied Linguistics, 13(1), 36-54.

Trent, J. (2011). Learning, teaching, and constructing identities: ESL pre-service teacher experiences during a short-term international experience programme. Asia Pacific Journal of Education, 31(2), 177-194. doi:10.1080/02188791.2011.566997

Vygotsky, L. S. (1978). Mind in society. Cambridge, MA: MIT Press.

Wenger, E. (1998). Communities of practice: Learning, meaning, and identity. Cambridge, UK: Cambridge University Press. 


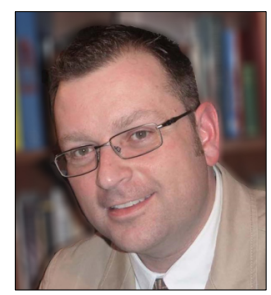

Scott Roy Douglas is an Associate Professor in the University of British Columbia's Okanagan School of Education. His focus is on English as an additional language teaching and learning, with research interests including short-term study abroad, teacher education, novice academic writing, and English for academic purposes materials development. He is the editor of the BC TEAL Journal. He is also the series editor and an author for Academic Inquiry: Writing for Post-secondary Success, published by Oxford University Press Canada.

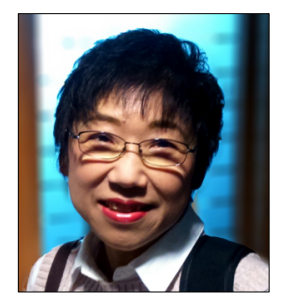

Fujiko Sano is a Professor of English language education in the Faculty of Foreign Studies at Tokoha University in Japan. Her research interests include second language acquisition (SLA), teacher education, and teaching writing in English as a foreign language (EFL). She has presented at conferences such as the British Association for Applied Linguistics, the American Association for Applied Linguistics, Task-Based Language Teaching, and the Japan Association of College English Teachers. Her recent work focuses on developing books for teachers of EFL from the SLA point of view. She has worked as the editor in chief for four books in Japan.

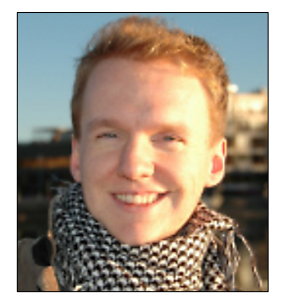

Mark Rosvold is a graduate student at UBC's Okanagan campus, where he is completing his MA (Interdisciplinary Graduate Studies). The scope of his research spans the fields of anthropology and education. He has also been a teaching assistant, research assistant, and cultural liaison for visiting English as an additional language and English for academic purposes students at the postsecondary level. Additionally, as a member of BC TEAL he has contributed to the provincial newsletter, volunteered as a peer reviewer for the journal, and presented on several occasions at conferences. 